\section{Mid-American Review of Sociology}

town was being run by a "weak-willed husband, subservient to the will of his wife," and Sir John was recalled from his position.

In fact, only one colonial wife was able to enter the public arena openly and effectively: Caroline Chisholm. Convinced in early adulthocd that her life was to be a "dedicated philanthropic endeavor," Caroline married her husband only after he agreed that she would be free to engage extensively in philanthropic work. Moreover, her marriage to a career soldier -- a man often away from home on long assignments-- provided her with the basic requisites for a successful public career: respectability, status, autonomy, freedom from frequent pregnancies, and an environment explicitly chosen to be "civilized." Caroline worked fervently to improve the conditions of young women of convict origin by rescuing them from poverty, early marriages, and prostitution, and she earned public support for her efforts. She provided work and training for women and urged them to rely on their "utilitarian value" rather their sexuality in finding a mate, as there could obviously be no real communion between a "highly-cultivated and well-informed man, and a weak and ignorant woman." Caroline saw her work as solving a crucial need in colonial society by creating a pool of decent, marriageable women.

Several lessons on the participation of women in the public arena and the merging of marriage, colonization and gender norms emerge from these stories. First, it would appear that women can perform extraordinary and crucial amounts of labor in the private arena without challenging assumptions about a woman's place, as such labor receives no public recognition. Charlotte Bussell worked diligently in the management of her husband's property and demonstrated business acumen that far excelled that of her husband. Yet, her private arena labor did not threaten the ideal of femininity nor jeopardize the imaginary line between the public and private. The entry of women in the public arena, however, was quite limited and governed by more stringent criteria. Only women who were morally beyond reproach could enter the public arena; their activities had to appear to be secondary to their domestic duties and they had to coincide with the family and gender ideals of colonization.

While the wives in this book chose to become colonists by their choice of husbands, they willingly endured the isolation, hardships, and sacrifices of colonial life and made enormous contributions to the goals of colonization. The marriages of these affluent colonists were based on free choice and infused with the language of romantic love and the belief in female subordination; yet, male colonists often were motivated to marry because they needed the labor and practical assistance of their wives and their marriages were partnerships rather than male-dominated units. Russell notes that these women "created their own space and their own sense of purpose," and in the process they were able to use and develop skills which contrasted sharply with notions of women as helpless, submissive, and dependent. There is little evidence, however, their the structural demands of colonial society or the creation of marriages that :ere economic partnerships influenced the gender ideologies of the day.
Accommodating Protest: Working Women, the New Veiling, and Change in Cairo, by Arlene Elowe Macleod. New York: Columbia University Press, 1991. 206 pp.

The role of women in Islamic cultures has gained considerable attention in recent years. As a case study of lower-middle-class working women in Cairo, Egypt, Accommodating Protest is limited in its generalizability. Nonetheless, Macleod's focus on the lives of educated, urban women in this particular setting provides interesting insights into the rationale for an emerging and complex phenomenon, called "new veiling" or "higab." To Macleod, this "higab" practice symbolizes women's behavior as a form of "protest" or "resistance," and simultaneously, as "accommodation" or "acceptance."

Aided by her Arab and American heritage, Macleod has done a superb job of providing perspectives on the everyday activities of this particular subculture in the context of the broader Egyptian Islamic culture. Through this detailed picture, based on field work with roughly 85 women in Cairo, she has been able to capture the essence of subtle interacting forces that are simultaneously shaping these women's identities and lives.

The book is divided into seven chapters and includes an extensive bibliography. The sections dealing with the social history of veiling are especially noteworthy. Macleod provides the reader with rich information on the varied definitions and functions of the veil throughout the history of the Middle East. In so doing, she also challenges some of the stereotypes that are common in the Western literature about the role of women, generally, and about veiling practices, specifically, in the Middle East.

Macleod focuses, in detail, on the new meaning of the veil in the subculture of lower-middle-class, Cairo working women: not as a symbol of "religious revivalism," but rather as part of a movement toward "cultural reformation" and returning "to a more authentic and culturally true way of life" (p. 111). Central, here, is the focus on culture and on identity, and not simply on religion. Indeed, Macleod notes that very few of the "veiling women" she studied "seem to be turning to religion in a genuine way" (p. 110).

Socioeconomic changes in Egypt have resulted in opportunities and options for women in the formal labor force. However, more recently, due to changes in the global economy and the consequent economic conditions in Egypt, these opportunities have changed, as women have been forced through "necessity" to become part of the formal labor force. As Macleod notes, "Clearly women face a crisis of cultural and personal identity, created by the new experience of working outside the home, which erodes women's traditional identity, without providing a reasonable alternative" (p. 116).

These lower-middle-class working women manifest "the clash of tradition and modernity" (p. 11). And "new veiling," according to Macleod, serves to reconcile the conflicting roles of "traditional mother and wife," on the one hand, and "working outside the home," on the other (p. 121). Further, in searching for a symbol that will capture the true value of these modern "working wife and mother" roles, the lower-middle-class women utilize the "veil" or "higab" as a 


\section{Mid-American Review of Sociology}

symbol in their "reconstruction of identity" (p. 161). As such, the "veil" serves as a means of balancing the conflicting roles of these women.

However, Macleod maintains that the "new veiling" represents "a double edged message." While it is a form of "protest," it is also a form of "accommodation" or "acquiescence" (pp. 137-138). It reflects a form of both protest against, and acquiescence to, unequal power relations in three different contexts: family, class, and global level. Within the family, "veiling" validates their identities as "good woman," "good wife," and "good mother," while working outside the home, and helps to enhance their power in this context. Also, this practice symbolically provides these women with a means to bring themselves closer to the middle class and to remove themselves farther away from lower-class women. On the global level, in turn, "higab" serves as a mechanism for affirmation or validation of their cultural and gender identity by protesting against "the loss of traditional values" brought on by the rise of "modernization and development" (p. 135).

According to Macleod, while the "veil" can be perceived as a sign of change, it also signals women's acceptance and conformity to traditionally defined gender roles. This, in turn, can lead to "reproduction of inequality" in the future. In explaining the meaning and the function of the "veil" for this particular category of women, Macleod emphasizes that this practice should not be mistaken for, or perceived as, simply "reactivation of tradition," "reactionary," "Islamic resurgence," "false- consciousness," or "religious revivalism." Rather, it is "voluntary" and is "based on personal reflection" (pp. 4, 14, 107, 109-111, 160).

Macleod's Accommodating Protest provides detailed, informative, and stimulating insights into how a particular group of Non-Western women--lower-middle-class working women--adjust to, or cope with, the conditions of their everyday lives. In so doing, she elaborates the dynamics of the interaction among gender, culture, religion, family, employment, and power relations. However, given that this is a case study based on a small number of women in Cairo, Egypt, the reader is clearly limited in generalizing Macleod's findings to the lives of the millions of other Moslem women, not only in Egypt, but in other nations in the Middle East, Africa, Southeast Asia, and so forth.

Nonetheless, the depth of the data and analysis that Macleod presents should stimulate continuing research and dialogue about the roles of women in the Third World, not solely Moslem women, but all Third World women. Accommodating Protest provides an especially valuable contribution to understanding the complexity of gender issues in cultural contexts.

University of Kansas

Mehrangiz Najafizadeh
Generalist Practice: A Task-Centered Approach, by Eleanor Reordon Tolson, William J. Reid, and Charles D. Garvin. New York: Columbia University Press, 1994. $431 \mathrm{pp}$.

Twenty-six years have elapsed since the introduction of task-centered casework as an individually-oriented approach to social work practice. During that time the approach has continued to evolve through the research of the original developers and other scholars. Today the approach is defined as a highly structured, empirically based, problem solving method of intervention in which change occurs through the use of tasks or activities designed to ameliorate the identified problems. These change activities can be developed from an array of practice approaches as well as from problem-solving activities. (p. 4).

The authors envisioned this text as being used in teaching undergraduates and entry level graduate classes. They are hopeful that this text will meet the accreditation standards of the Council on Social Work Education for providing a generalist perspective of practice with different size client systems. They are also hopeful that the combination of the generalist framework, the integration of tested task-centered treatment directives across and within different size client systems and a numbering system that permits content to be studied by topic or as a complete work. It will also assist practice instructors to meet the challenge of teaching an integrated approach to helping without sacrificing skill mastery.

This book is systematically divided into four major parts which are further divided into chapters which focus on practice with all size client systems (individuals, families, groups, and large systems). The chapters, with the exception of the two dealing with larger systems, described different phases of treatment with a particular client system. A case illustration concludes the description of work with each of the systems. The two chapters on larger systems (human services organizations and communities are written by contributing authors).

On the whole, the book is clearly articulated, orderly presented and very readable. Evidence exists throughout the text of the author's work over the years to improve treatment procedures and to seek new applications of the approach. Obviously, one cannot propose an integrated approach to practice without regard for many of the essential elements of effective practice. For example, the concept of task has been more broadly defined to include more than what clients think they must do to alleviate the problem (p. 73). Also, two additional categories of problems, decision making problems, and psychological or behavioral problems not classified have been added to the original typology. Perhaps a more sweeping change has been in moving toward marrying this approach to generalist practice--an approach that is applied to all client populations rather they are capable identifying and clearly articulating their target problem. The authors address this concern by suggesting the use of referrals and or the use of a different practice approach. It is such suggestions that beg the question: How is the task-centered approach different from a goal-oriented, taskdirected approach? It would appear that good generalist practice that is effectively done is not only goal-oriented and task-directed, but also focuses on the client's strengths. This reviewer believes that the primary way that one achieves this 